MAGDALENA BEDNORZ

Faculty of Humanities

University of Silesia, Poland
Images

vol. XXIX/no. 38

Poznań 2021

ISSN 1731-45OX

\title{
Heroine's journey to love: Spatial rhetoric in romantic subplots in BioWare's fantasy RPGs
}

\begin{abstract}
Bednorz Magdalena, Heroine's journey to love: Spatial rhetoric in romantic subplots in BioWare's fantasy RPGs. "Images" vol. XXIX, no. 38. Poznań 2021. Adam Mickiewicz University Press. Pp. 191-204. ISSN 1731-450X. DOI 10.14746/i.2021.38.12.

This article explores the potential of digital games to encode references encompassing specific cultural ideas of romantic love within their spatial structures, thus helping guide the player's interpretation of romance as they interact with and move through those spaces. It undertakes an analysis of romantic subplots in BioWare's fantasy role-playing games, specifically those which reappropriate the courtly love trope, and discusses elements of that remediation which rely heavily on spatial metaphors and structures, including the shared experience of heroic journey, the role of questing for the development of romance, and spatial positioning of lovers on the game map. Through its analysis, the article explores how digital games can employ spatial rhetoric while approaching topics of love, and how they are equipped to represent the materiality and spatiality of love and love narratives.
\end{abstract}

KEYworDs: digital games, digital spaces, love, courtly love, Bioware

As interest in the discourses and depictions of love has been growing in the fields of cultural and social studies, [1] so too has the attention placed on the material and spatial aspects of emotional expression. Not only is this attention turned towards the ways in which love materializes through objects and material gestures, [2] but also towards the geographies of love - the spaces in which romantic relationships are developed and feelings of love expressed, including "discursive spaces, such as representations of love in film, on billboards, in magazines and on the internet." [3] Simultaneously, the same critical turn towards ways of communicating romantic love has sparked interest in analyses of how specific media utilize their unique methods of expression to relay and represent the emotional and the romantic.[4] Such interest often includes a focus on the relationship between the medium and the

\section{Introduction}

[3] C-A. Morrison, L. Johnston, R. Longhurst, Critical geographies of love as spatial, relational and political, "Progress in Human Geography" 2012, vol. 37, no. 4, p. 512.

[4] See: L. Mackinnon, Love machines and the tinder bot bildungsroman, "e-flux journal" 2016, \#7, June 21, <https://www.e-flux.comjournal/74/59802/lovemachines-and-the-tinder-bot-bildungsroman/>, accessed: 24.01.2021. 
romantic codes it distributes, and the rhetorical potential of specific devices to facilitate cultural ideas of romantic love.[5]

In accordance with these perspectives, the present article undertakes an analysis of selected examples of digital games in order to explore how they employ one of their defining qualities and means of expression, namely their spatiality, in order to craft representations of romantic relationships. The analysis focuses on three games by BioWare studio, specifically on the use of the themes associated with courtly love as they are employed within the games' female-character-oriented romances. The choice to focus the analysis on specific romantic subplots in BioWare's fantasy RPGs stems from the clear incorporation of the courtly themes within those plots, as well as from the broad and varied use of spatiality within the discussed titles. In turn, the choice to place courtly love at the heart of the analysis is motivated by the pre-existing themes of distance and travel within the popular understanding of the courtly love trope, which in turn renders its remediations to the digital medium a compelling case for investigating how such reworkings use spatial structures, rules, and facilitation of movement, along with the narrative reimagining. In doing so, the article aims to explore the potential of digital games to encode references encompassing specific cultural ideas of romantic love within their spatial structures, and, consequently, their potential to mediate and represent the spatial, material aspect of romantic expression.

Spatiality of digital games
The existing body of research concerning romantic expression and love narratives in digital games has been expanding in recent years.[6] Accordingly to the inter- and cross-disciplinary character of the field of game studies, the scholarly takes on love and games range in focus from social aspects of play and player interactions, through emotions players develop for the games themselves, to the expressive means of representations games possess to depict love and their application in particular titles.[7] Among the latter approaches, the scrutinized tools of expression vary heavily[8]; depending on the angle of the approach, as well as the genre and design choices within the analyzed games, studies may focus more on visual representation, on semiotics, mechanics, narrative design, or the tension between different means of expression in particular games.[9] However, there is still
[5] Ibidem.

[6] See: J. Enevold, E. MacCallum-Stewart (eds.) Game Love: Essays on play and affection, Jefferson 2015; H. McDonald (ed.) Digital Love: Romance and Sexuality in Video Games, Boca Raton - London New York 2017.

[7] See: J. Enevold, Game Love - A Categorization Model, Gaming Moms 20o8, <http://gamingmoms. wordpress.com/publications/>, accessed: 24.01.2021. [8] See examples: S. Möring, Simulated metaphors of love: How the marriage applies metaphors to simulate a love relationship, [in:] Game Love: Essays on play and affection, eds. J. Enevold, E. MacCallum-Stewart, Jefferson 2015, pp. 252-277; S.Ch. Ganzon, Investing time for your in-game boyfriends and BFFs: Time as commodity and the simulation of emotional labor in mystic messenger, "Games and Culture" 2019, vol. 14, is. 2 , pp. $139-153$.

[9] Even while exploring similar titles, scholar may approach them from different angles, as evidenced 
very little analysis done on the spatial aspects of romantic expression in games. This article, following the approaches focusing on the means of romantic representation, but focusing mainly on the spatial aspects of the discussed romantic plotlines, aims to address that blank spot in the existing research.

The potential of game spaces to convey and communicate meaning to the players, as well as the uniqueness of the digital medium to craft meaningful experiences through spatial structures, employment of boundaries, rules guiding movement, and the visual representation of those spaces on the interface, has been a long established topic of conversation in the field of game studies. Not only is spatiality considered to be one of the defining qualities of the medium, [10] but it also has been established as a quality crucial in the process of generating player involvement[11] and allowing the stories to be unfolded during gameplay.

That unique potential is usually assigned to the ability of the digital games to evoke mental representations and realize them within the interface, while at the same time structuring the interactive experience of the represented space as the players engage with it in real-time. Linking that ability with the generation of stories, Sebastian Domsch writes, "Game spaces are spaces that we can experience through our presence within them as other spaces. And this otherness is conveyed by giving this space a story of its own, a story that the player will come to understand through experience and influence through agency." [12] Domsch links player agency and the interactivity of gameplay, realized as inhabiting game space, with the emergence of stories. The same sentiment seems to be expressed in a much earlier text written by Henry Jenkins on the subject of environmental storytelling[13]; that is, on the way games communicate stories by the arrangement of objects within spaces. Jenkins emphasizes the need to think of narrative design in games in more architectural terms, rather than through borrowing classic storytelling techniques from other media, thus assigning game spaces a role as main generators of game narratives. Clara Fernández-Vara shares that view, claiming that "spaces are one of the obvious bridges between narrative and games." [14] Additionally, Fernández-Vara

by two chapters of "Game Love" specifically relevant to this article, as the game series they discuss is also analyzed here - namely, Annika Waern's and Peter Kelly's. While Waern focuses more on the affective power of narrative development and role-play in Dragon Age: Origins, Kelly discusses structural patterning of romance in Dragon Age 2. (J. Enevold, E. MacCallum-Stewart, op.cit.).

[10] See: J. Murray, Hamlet on the Holodeck: The future of narrative in cyberspace, New York 1997.

[11] See: G. Calleja, In-Game. From immersion to incorporation, Cambridge - London 2011, pp. 55, 73-92.
[12] S. Domsch, Space and narrative in computer games, [in:] Ludotopia, eds. E. Aarseth, S. Günzel, New York 2019, p. 105.

[13] H. Jenkins, Game design as narrative architecture, 2004, <http://web.mit.edu/ 21fms/People/henry3/ games\&narrative.html>, accessed: 24.01.2021.

[14] C. Fernández-Vara, Game spaces speak volumes: indexical storytelling, Proceedings of 2011 DiGRA International Conference: Think Design Play, 2011, p. 1, $<$ http://www.digra.org/wp-content/uploads/digital-library/Game-Spaces-Speak-Volumes.pdf $>$. 
extends the idea of environmental storytelling - which she calls indexical storytelling - to include not just the spatial arrangement of objects, but also the strategies by which game spaces can be navigated, since for her, it is the navigability of digital environments that distinguishes their spatial representations from other media.

Fernández-Vara's conclusion seems to be supported by Niklas Schrape as he explores the inherent ability of games to create meanings through spatial organization and movement facilitation, when he writes "[a]s simulations, games contain models. A quick glance on architecture shows that a model can be spatial - not only in the metaphorical sense of the possibility space, but as actual space of movement." [15] However, Schrape is less interested in the storytelling potential of the architectural models present in games, and more in the rhetorical power such potential represents, as he adds "[f]ollowing Bogost and Frasca, such spatial models necessarily have to be subjective and ideological." [16] Schrape argues that digital game spaces, by combining "a mimetic presentation, which guides the player's understanding and a systemic structure that constrains and channels play," [17] guide both play and player interpretation; they use semantic fields, topography and constraints to guide the player's experience, thus serving as powerful tools for making persuasive statements and modelling real-life socio-cultural processes.

If we follow the proposition that game spaces, in their formal and mimetic elements, can model processes and situations for the player to relate their real-world experiences to, and can motivate certain understandings of those processes, we can apply a similar pattern in reasoning to those models which thematize processes involving emotions and affects, especially models that engage in spatial metaphors. In other words, even though Schrape illustrates his argument through the use of spatial game structures to represent geopolitical conflicts, that same reasoning can be extended to the employment of spatial means of expression in the depictions of romantic love, a notion which I will try to explore in the following analysis.

Spatiality of (courtly) love in BioWare's fantasy RPGs
One of the most recognizable examples of employing themes concerning spaces and movement within love narratives can be traced to the courtly love tradition. Courtly love is understood here as a set of references and tropes, loosely based on the chivalric tradition of middle-ages and filtered through both romantic and modern interpretations as they circulate in popular culture, rather than a medieval genre of poetry. Not only is this type of courtly love heavily associated with both chivalric romance and adventure stories, engaging with the
[15] N. Schrape, The rhetoric of game space: Lotman's spatial semantics as a method for analysing videogames, [in:] Ludotopia, eds. E. Aarseth, S. Günzel, New York 2019, p. 249.
[16] Ibidem, p. 249.

[17] Ibidem, p. 245. 
themes of travel, quest, separation or rescue,[18] but it also serves as one of the most popular, often idealized, themes in cultural depictions of romantic love, making it a compelling case to analyze while discussing the role of spatiality within romantic narratives.

Simultaneously, the popularity of the trope allows for a detailed investigation of contemporary reimagining and remediation of courtly love narratives in various media, including digital games. This popularity can be directly traced to the larger scope of medievalizations reworkings of how we imagine Middle Ages and the cultural traditions of that time - circulating in popular culture, with a particularly strong presence in the fantasy genre.[19] On the one hand, such invocations of medieval traditions draw inspiration from very recognizable, culturally-established references to and associations with the Middle Ages; on the other, they rework them freely to adjust to the modern understanding, which often results in medievalisms serving as tools to make persuasive claims about the socio-cultural processes of the present, and the texts of the culture that employ them - a representation of the contemporary understanding of how those processes work. [20]

As one of the most discernable medievalisms, the trope of courtly love has a strong presence in contemporary culture, including fantasy books and movies, which employ themes of adventure, quest, sacrifice, transformation through love, proving oneself to deserve the love of the lady,[21] and a set of characters consisting of the young, brave knight and the patient, often unattainable, noble lady.[22] Those themes can also be traced to a number of renderings in digital games, and among those, are also present in the subplots of fantasy games produced by $\mathrm{Bi}$ oWare, a Canadian studio specializing in role-playing games, which are known to often include in-game romances. As Bioware's romances rely on both narrative and formal gameplay elements to craft the intended imaginings of love, its games prove a compelling material to study the interactions between various medium-specific means of expression as they communicate meanings concerning romantic relationships. Among those means of expression is spatiality, understood both in terms of the game world and spatial structures, which allows for examining the links between the romantic and the spatial - the links which should allow for illustrating how spatial elements can contribute to the process of communication and depiction of love in games, and which the following analysis will therefore focus on.

One of the oldest and clearest examples of the use of courtly love trope within BioWare's romance subplots can be found in Baldur's Gate II: Shadows of Amn. Set in Forgotten Realms - a classic fantasy

[18] J. Tolmie, Medievalism and the fantasy heroine, "Journal of Gender Studies" 2006, vol. 15, no. 2, p. 149. [19] Ibidem.

[20] E. Fay, Romantic Medievalism: History and the romantic literary ideal, London 2002.

[21] R.J. Cormier, "You Make Me Want to Be a Better
Man": Courtly values revived in modern film, [in:] The Legacy of Courtly Literature, eds. D. Nelson-Campbell, R. Cholakian, London 2017, pp. 77-88.

[22] J. Goodman Wollock, Courtly love, [in:] The Encyclopedia of Medieval Literature in Britain, eds. S. Echard, R. Rouse, New York 2017, pp. 2-4. 
campaign setting - and adhering to the genre conventions of high fantasy, the game constitutes a second installment of the series following the adventures of the Child of Bhaal. The main plot of the story concerns encounters between the protagonist and Jon Irenicus, a power-hungry mage intent on testing and harnessing the Child of Bhaal's power for his own use. In order to resolve the conflict, the protagonist needs to overcome a series of challenges, usually in the form of quest-adventures. During the course of the game, they ally themselves with several possible companions who help them in their travels. Several of those companions are romanceable; there is an option to pursue a romantic relationship with them. Most of those characters have preferences; the possibility to flirt with them is dependent on the player character's race and gender. Consequently, three out of four romance options are reserved for male characters, while only one of the companions is romanceable by a female player character ("PC").

Anomen, a young warrior/cleric and a knight-to-be, invokes references to the trope of courtly love, and chivalric romances in general, from the very moment the PC meets him. Not only is he on a mission to prove himself to the Order of the Radiant Heart - an order of lawful, noble warriors - but he also immediately starts using "my lady" to address the female PC, asking her about the purity of her intentions and boasting about his intent to prove himself by ridding the world of evil. This introductory dialogue and speech-pattern positions him very clearly as the archetypical knight in a courtly romance, and the protagonist must serve as his ideal virtuous lady if she is to stand any chance at winning his heart.

Importantly, Anomen very quickly introduces the theme of travelling as an important figure within the romance as well. The main body of the romance happens through conversations between Anomen and the female PC. He initiates the very first of these love talks with the following question: "I prithee, my lady [...] it fills me with no small amount of wonder that you have not asked me of my journeys ere we met? We have traveled a short while, and yet we know next to nothing of each other." [23] This way of beginning the romance not only strengthens the association of Anomen and the female PC with the main characters of a heroic chivalric quest, but also sets expectations of the importance of their further journey together: the spatial journey through the game landscape becomes equated with the characters' emotional journey of getting to know each other. That sentiment, in turn, is mirrored by the procedural layer of the romance. As mentioned before, the main body of the romance happens through love talks; those love talks are triggered in regular intervals counted against the real-time spent in the game. Therefore, in order to keep the love talks happening and advance the romance between Anomen and the PC, the player needs

[23] BioWare, Baldur's Gate II: Shadows of Amn, Black Isle Studios 2000. 
to keep Anomen in the party as the PC's companion throughout their journeys. Moreover, some of those conversations require that additional conditions be met: for example, specific maps need to be entered, or others need to be left (e.g., being in a combat-oriented dungeon map will prevent most love talks from happening), which strengthens the space-reliant undercurrent of the entire romance. Such spatial distribution of love talk triggers throughout the game world, along with the passage of real-time as a core factor in the romance, further strengthens the impression of the romantic relationship as a slow, processual ordeal that must be tested against a variety of different circumstances and environments to fully develop.

In other words, by crafting a spatial undercurrent through both formal and narrative layers of the game, Anomen's romance evokes the sense of a romantic relationship as a gradual process of growing together and learning about each other by encountering new places and crossing subsequent thresholds, as the development of the romance mirrors the spatial progress within the game and the overall progress within the larger journey of the main plot arc. In doing so, the romantic arc very clearly references a common cultural metaphor of love, namely that of love as a journey, in which the literal distance the parties in the relationship travel is analogous to the emotional one.[24] By employing formal, medium-specific means of expression to communicate this sentiment, along with the overall narrative setup of the game, Anomen's romance explores the potential of digital spatial structures to reference cultural ideas of love, and in doing so, strengthens the metaphor by doubling down on the rhetorical tools through which it is communicated.

A similar process can be traced to another BioWare fantasy game which employs courtly love references within one of its main romances. Set in the dark fantasy world of Thedas, Dragon Age: Origins presents the story of the Grey Wardens, an order of legendary warriors tasked with fighting creatures called the Darkspawn. The PC is recruited to join this order early in the game, and soon thereafter, a battle against the monsters wipes out most of their fellow Wardens. In the aftermath, the PC is tasked with gathering allies to stop the upcoming Darkspawn invasion. The only other Grey Warden to survive the massacre, Alistair, joins them in the task.

Alistair, even though slightly more experienced as a Warden than the PC, is still a rather fresh addition to the order. This inexperience, coupled with his prior knight-templar training, matches him to the trope of a young, noble knight on his way to prove himself. Moreover, like Anomen, Alistair can only be romanced by a female PC, unlike three remaining romanceable characters, which can be pursued either solely by a male character, or by both genders. While pursuing Alistair's 
romance, the aesthetic trappings of the courtly love are easily noticeable: not only does he fit the knightly archetype, both in terms of his backstory and the warrior class that determines his gameplay abilities, but he also attempts to approach the female PC with a show of courtly manners, even going as far as presenting her with a rose as a token of his affection. However, while Anomen's romance serves as an additional subplot to the overarching story of Shadows of Amn, and, much like other companions from that game, Anomen does not necessarily play a major part in the main events outside of his role as a companion, the same cannot be said about Alistair. Not only is he the only other surviving Warden, which places him near the center of the main heroic story arc, but he is also eventually revealed as an important factor in the game's political intrigue. His role in crucial narrative moments of the game renders him not only influential as a character within the story, but also as a quest-giver, in his frequent inspiration of possible directions the PC can take.

The quests instigated by Alistair vary in scope throughout the game. For example, Alistair initiates a quest concerning one of the major arcs in the main story, by pointing the PC toward his childhood home of Redcliffe Village as a potential location to search for influential allies in their fight; visiting Redcliffe reveals major problems the village is facing and leads to multiple further gameplay arcs. In contrast, Alistair's personal quest involves simply accompanying him to visit and confront his half-sister, in order to find some answers about his past and his family. Importantly, both those quests share significant personal elements, crucial for Alistair's character development. While visiting Redcliffe, Alistair confides in the PC and shares elements of his backstory, revealing he is a bastard son of the late king and therefore a crucial part of the ongoing political situation; the revelation itself becomes a first step on his personal journey of dealing with his past. Similarly, while visiting his sister, Alistair undergoes a character-defining moment, which may result in him becoming either more selfish and more confident or more reliant on others, depending on what the PC says to him.

Of course, all these quests - and Alistair's involvement in them are part of the game, even without pursuing a romance. However, the PC's potential romantic relationship with Alistair is highly influenced by how the quests play out. First, the very possibility of Alistair becoming a love interest is determined by his approval rating. As the majority of the approval points are triggered by the decisions made within the game, it is advisable to keep Alistair as an active companion in the party. Second, travelling to specific places unlocks pieces of information and reactions, as described above, which not only adds to the content of the romance, but also determines the direction in which it may resolve, as in the case with his character change, which influences whether Alistair and the PC stay together at the end of the game. Romance, then, becomes inherently linked to Alistair's quests, both in terms of 
their narrative content and spatial progression: progress within the game space mirrors the progress of the relationship between the lovers, while the outcomes of decisions made during the journey are measured against Alistair's approval score.

The link between questing and romantic endeavors has been long established in the courtly and chivalric tradition. In the broadest understanding of the quest as a narrative structure, as described by Joseph Campbell in his study on the monomyth, it concerns the story of a hero who ventures forth into a world different from their own, often supernatural in nature, to face the challenges this new region presents, prove themselves and gain a reward.[25] Within the chivalric and courtly tradition, however, such challenges are often faced as a service of love, a way to establish a lover's worth and thereby gain the affection of the lady.[26] It is no surprise, then, that a similar structure has been applied within the romances of games, especially those that already draw heavily on the courtly tradition. What distinguishes the romantic quests in the digital games discussed is their employment of medium-specific means of expression; namely, the incorporation of the quest logic within the formal, rule-oriented layer of the game. Again, the link between the monomythical tradition and game structures employing quests is not a new idea. While discussing the role of quests as units of game activity, game scholars stress the influences of the long tradition of quest narratives, as well as the analogies between the themes of those narratives and the tasks the player is asked to enact within the game-quests, including overcoming challenges in order to reach a specific goal[27] and traversing the game-space in order to do so.[28] Significantly, such approaches stress that in digital games, quests work as both narrative structures and mechanics-based activities, thus combining the issues the hero is facing with the challenge the gameplay presents to the audience. The same logic, applied to subplots concerning love, inherently links the effort of gameplay with the themes communicated through the narrative; namely, with establishing a romantic relationship.

Consequently, the use of quests in Dragon Age: Origins as a means to enact and measure the progress of a romantic subplot leads to the association of romance with a challenge, in which the PC has to prove herself against Alistair's approval score by providing him emotional support and by travelling to places he points to as the settings of his personal questline. Simultaneously, as is the tradition of quests, the reward for these challenges is an important part of the experience, which renders winning Alistair's heart an expected prize, as in the case of

[25] J. Campbell, The Hero with a Thousand Faces, New York 1949.

[26] R. Boase, The Origin and Meaning of Courtly Love: A critical study of european scholarship, Manchester 1977; B. Tuchman, A Distant Mirror: The calamitous 14th century, New York 1978.
[27] J. Howard, Quests: Design, theory, and history in games and narratives, Natick 2008.

[28] E. Aarseth, Quest games as post-narrative discourse, [in:] Narrative Across Media: The languages of storytelling, ed. M.-L. Ryan, Lincoln 2004, pp. 361-376. 
gaining insight into his character, shaping him into the man the PC wants him to be, or simply triggering love scenes and finally receiving a love confession. Thus, by linking the challenging nature of questing and travel with the romantic context, by associating the need to prove oneself with the possibility of building up romantic interest, Alistair's romance encodes love as a set of challenges to overcome in order to gain the object of affection, crafting the image of romantic love as something that requires constant effort. That effort in Dragon Age: Origins is calculated against spatial progression and gameplay progression, as well as the progression of the plot. Not only does the game require the PC to travel with Alistair and gradually gain his approval (as the possibilities to do so are scattered throughout the game world), but it also associates the basic unit of game activity (i.e., the quest) with both romantic progression and the motif of travel. In doing so, the game intertwines its various means of expression - the spatial structures and metaphors, the narrative, the rules - and, by employing them within romantic context, channels the effort they generate within gameplay towards the understanding of love not just as a reward, but as a quest in its own right.

Dragon Age: Inquisition similarly employs the courtly love trope to present the analogy between love and effort, albeit through vastly different means. Set in the same fictional world as Dragon Age: Origins, Inquisition is the third installment in the Dragon Age series. The player takes on the PC role of the Inquisitor, leader of the eponymous, semi-religious, semi-military organization, both during their rise to power and on a mission to close a dangerous interdimensional rift and fight the monster responsible for opening it. The overall construction of the plot, as well as the division thereof into smaller quest-adventures, is consistent with that of its predecessor. Similarly, too, Inquisition introduces a plethora of companions who assist the PC during their adventures, and the game offers a variety of romance options for both genders. However, unlike the games discussed above, Inquisition broadens the scope of those options to characters who cannot assist the protagonist directly by joining their party. One of these is Cullen, the PC's military advisor.

Cullen, unlike Anomen and Alistair, is an established character throughout the series by the time he is given a romantic arc, which renders him more experienced than the archetypical young knight. However, he still fits within the same set of courtly references. He certainly evokes the trope of a knight, as he is a retired Templar and the current head of the Inquisition's military forces; he is only romanceable by a female PC, whom he addresses as "Lady"; and he undergoes a personal arc of self-doubt, redemption, and self-actualization. The main difference that sets Cullen apart is his role as the advisor to the PC: as a non-companion character, Cullen spends nearly the entirety of the game outside of the PC's party, in the main base of Inquisition's operations. This placement renders Cullen stationary, only able to be talked to during important narrative events or by encountering him on 
the main fortress' map. Thus, in order to trigger his personal conversations, select romantic dialogue options, and fulfill his personal quests, the PC has to actively seek him out whenever she visits. Moreover as Cullen usually occupies a rather desolate and remote place within the main fortress, she needs to go out of her way to do so. As such, by forcing the PC to navigate the environment, his placement by itself works as a device to generate effort on the part of both the PC and the player, creating what Gordon Calleja calls "meaningful exertion of agency." [29] This term refers to the instance of player's influence over what happens within the game environment; an influence, which in this particular case is linked to spatial navigation, one of the aspects of player involvement in Calleja's model,[30] and which in Cullen's romance results in a direct analogy between the emotional and kinetic effort. This analogy is stressed even more by the context of a reward at the end of the exercise in kinetic effort: namely, when the PC finally reaches Cullen, the dialogue choices required for the romance to continue often require some semblance of consolation or advice. These dialogue requirements further explore the theme of emotional work in a romantic relationship while mirroring the effort inspired by the game's spatial organization.

Notably, this divide between the active PC, who is able to move through the game environment, and the stationary, reactive Cullen subverts the usual gender roles assigned within the courtly love trope, placing Cullen in the position usually occupied by the unapproachable, unattainable lady who inspires masculine longing and only shows her affection to her lover after he proves himself and his worth.[31] The consequence of this subversion are twofold. On the one hand, due to the agency shift - in which even the possibility to traverse the game space is instrumental - the female PC occupies a seemingly more empowered role than that of a stationary love interest. On the other hand, much like in the case of Alistair's personal quests, that agency comes with the responsibility of initiating and continuing the romantic relationship. The personal quests of all the discussed characters require the female PC to exercise support, ground the lovers in their convictions, advise them, and help them overcome their weaknesses. Taken in this context, the aforementioned responsibility also assigns the female PC the duty of emotionally managing the relationship, drawing references to the general cultural tendency in which, while dealing with monomythic enactments, the quest of a heroine's journey tests her intuition and insight, while the parallel hero undergoes a test of logic and order.[32] Within Cullen's romance, this same set of cultural associations is employed through the use of structural spatial elements which facilitate

[29] G. Calleja, op.cit., p. 55.

[30] Ibidem, pp. 73-92.

[31] R. Boase, op.cit., p. 83; J. Goodman Wollock, op.cit.
[32] See: V.E. Frankel, From Girl to Goddess: The heroine's journey through myth and legend, Jefferson 2010. 
agency, only then to recontextualize it as an emotional responsibility to test insight and support. It serves as an illustration of how, while the spatial structures and the facilitation of movement are equipped to inspire engaging, emotional responses in the players, the specific narrative context in which they are played out motivates particular understandings of romantic relationships, and of how the tension between the formal and mimetic layers of game's spatiality can serve as a tool to make persuasive claims about emotional processes such as love.

\section{Conclusions}

The examples discussed above show how digital game spaces can function as rhetorical tools for eliciting emotional responses in their audiences, as well as encoding specific cultural ideas associated with romantic love. The range of cultural codes they evoke includes the metaphorization of a romantic relationship as a shared, challenging experience of journeying and crossing subsequent thresholds together; the idea of love as a process which requires effort of going out of one's way to pursue it; and the association of a reward for that effort with the establishment of a relationship. This list is not exhaustive, and further links between the game spaces and depictions of romantic love could be explored, especially by extending the subject of the analysis to more titles and other game genres. Similarly, the subject of this article constitutes a narrow case study of a Western cultural theme as applied to one specific type of games, and as such, it does not allow for answering all the concerns the topic of culturally-rendered intersections between the spatial and the romantic can pose, and further research on the topic would be of great value. However, even in its constrained scope, the analysis conducted above may serve as an illustration of the potential of games' spatial aspects to help guide the player's understanding of specific interpretations of love and romance - through spatial organization, structuring movement, generating effort, enforcing boundaries, and the placement of characters or narrative triggers on the game map, as well as through the specifics of the game world, spatial and narrative elements, metaphors, and cultural references. Of course, those spatial means of expression are heavily reliant on the context in which they are placed and played out, so on the narrative, rules, and mechanics of the depicted romance. Only the mutual interactions between these aspects help craft specific models of romantic relationships, drawing from the sets of associations already existing within cultural circulation and discourses of love, to be played out by the audience interacting with games and game spaces while exploring romance subplots. In doing so, games place themselves within the larger body of romantic fiction, as they both use and redistribute the codes of romantic love. In turn, by linking the romantic with formal, medium-specific methods, not only do they demonstrate the rhetorical power of game structures and game spaces to communicate emotional meanings, but they also emphasize how uniquely the digital medium is equipped to explore the role of the material and the spatial in the discourses and narratives of love. 
Aarseth E., Quest games as post-narrative discourse, [in:] Narrative Across Media: The languages of storytelling, ed. M.-L. Ryan, Lincoln 2004, pp. 361-376

BioWare, Dragon Age: Origins, Electronic Arts 2009

BioWare, Dragon Age Inquisition, Electronic Arts 2014

BioWare, Baldur's Gate II: Shadows of Amn, Black Isle Studios 2000

Boase R., The Origin and Meaning of Courtly Love: A critical study of European scholarship, Manchester 1977

Calleja G., In-Game. From immersion to incorporation, Cambridge - London 2011

Campbell J., The Hero with a Thousand Faces, New York 1949

Cormier R.J., "You Make Me Want to Be a Better Man": Courtly values revived in modern film, [in:] The Legacy of Courtly Literature, eds. D. Nelson-Campbell, R. Cholakian, London 2017, pp. 77-88. DOI 10.1007/978-3-319-60729-0_5

Domsch S., Space and narrative in computer games, [in:] Ludotopia, eds. E. Aarseth, S. Günzel, New York 2019, pp. 103-123. DOI 10.14361/9783839447307006

Enevold J., Game Love - A Categorization Model, Gaming Moms 2008, <http:// gamingmoms.wordpress.com/publications/>

Enevold J., MacCallum-Stewart E. (eds.), Game Love: Essays on play and affection, Jefferson 2015

Fay E., Romantic Medievalism: History and the romantic literary ideal, London 2002

Fernández-Vara C., Game spaces speak volumes: indexical storytelling, [in:] Proceedings of 2011 DiGRA International Conference: Think Design Play, 2011. <http://www.digra.org/wp-content/uploads/digital-library/Game-Spaces-Speak-Volumes.pdf>

Frankel V.E., From Girl to Goddess: The heroine's journey through myth and legend, Jefferson 2010

Ganzon S.Ch., Investing time for your in-game boyfriends and BFFs: Time as commodity and the simulation of emotional labor in mystic messenger, "Games and Culture" 2019, vol. 14, is. 2, pp. 139-153

Goodman Wollock J., Courtly love, [in:] The Encyclopedia of Medieval Literature in Britain, eds. S. Echard, R. Rouse, New York 2017. DOI: 10.1002/9781118396957. wbemlb245

Gratzke M., Love is what people say it is: performativity and narrativity in critical love studies, "Journal of Popular Romance Studies" 2017, is. 6, pp. 1-20

Howard J., Quests: Design, theory, and history in games and narratives, Natick 2008

Jenkins H., Game design as narrative architecture, 2004, <http://web.mit.edu/ 21fms/ People/henry3/games\&narrative.html>

Lakoff G., Johnson M., Metaphors We Live By, Chicago 1980

Mackinnon L., Love machines and the tinder bot bildungsroman, "e-flux journal" 2016, \#7, June 21, <https://www.e-flux.com/journal/74/59802/love-machines-and-the-tinder-bot-bildungsroman/>

Malinowska A., Gratzke M. (eds.), The Materiality of Love: Essays on Affection and Cultural Practice, New York 2017

McDonald H. (ed.), Digital Love: Romance and sexuality in video games, Boca Raton - London - New York 2017

Morrison C.-A., Johnston L., Longhurst R., Critical geographies of love as spatial, relational and political, "Progress in Human Geography" 2012, vol. 37, no. 4, pp. 505-521. DOI 10.1177/0309132512462513

Möring S., Simulated metaphors of love: How the marriage applies metaphors to simulate a love relationship, [in:] Game Love: Essays on Play and Affection, eds. J. Enevold, E. MacCallum-Stewart, Jefferson 2015, pp. 252-277

Murray J., Hamlet on the Holodeck: The future of narrative in cyberspace, New York 1997 
Schrape N., The rhetoric of game space: Lotman's spatial semantics as a method for analysing videogames, [in:] Ludotopia, eds. E. Aarseth, S. Günzel, New York 2019, pp. 245-269, DOI: 10.14361/9783839447307-014

Tolmie J., Medievalism and the fantasy heroine, "Journal of Gender Studies" 2006, vol. 15, no. 2, pp. 145-158. DOI: 10.1080/09589230600720042

Tuchman B., A Distant Mirror: The calamitous 14th century, New York 1978 